\title{
The Impact of Exposure to Unrealistically High Beauty Standards on Inhibitory Control
}

\author{
Leila Selimbegović ${ }^{1}$, Catherine Juneau ${ }^{2}$, Ludovic Ferrand ${ }^{2}$, Nicolas Spatola ${ }^{2}$, \\ Maria Augustinova ${ }^{2,3}$
}

${ }^{1}$ CNRS, Université de Poitiers, Université de Tours

${ }^{2}$ Université Clermont Auvergne, CNRS, LAPSCO, F-63000 Clermont-Ferrand, France ${ }^{3}$ Normandie Université, UNIROUEN, CRFDP, F-76000 Rouen, France

Running head: Exposure to beauty standards and inhibitory control

Article published in L'Année Psychologique (2019), volume 119, pp. 473-493.

\begin{abstract}
Author note
Leila Selimbegović, Département de psychologie, Université de Poitiers, et Centre de Recherches sur la Cognition et l'Apprentissage, UMR-CNRS 7295, MSHS, Bat A5, 5 rue Théodore Lefebvre, TSA 21103, 86073 Poitiers CEDEX, France. Email: leila.selimbegovic@univ-poitiers.fr, The authors declare that there are no potential conflicts of interest with respect to the research, authorship, and/or publication of this article.
\end{abstract}




\title{
EXPOSURE TO BEAUTY STANDARDS AND INHIBITORY CONTROL
}

\begin{abstract}
Common processes underlying effects of exposure to unattainable beauty standards and their regulation are currently poorly understood. Therefore, the present study investigated the impact of this exposure on executive inhibitory control. Between two blocks of a semantic Stroop task, seventy-two healthy young women were exposed to pictures of a thin beauty model (vs. control pictures). Exposure to the model did not affect the level of semantic Stroop interference. However, standard Stroop interference (which includes an inhibitory control component) increased for control participants in the second block, while participants exposed to the model maintained the same level of standard Stroop interference across the two blocks. These results suggest that comparison with an unrealistically high beauty standard facilitates the deployment of inhibitory control across time. Discussion focuses on the potential role of the motivation to avoid aversive self-awareness and negative emotions in these effects and their practical implications.
\end{abstract}

Keywords: inhibitory control, Stroop interference, beauty standards, social comparison, escape theory 


\section{EXPOSURE TO BEAUTY STANDARDS AND INHIBITORY CONTROL}

\section{L'impact de l'exposition aux standards de beauté irréalistes sur le contrôle inhibiteur}

A ce jour, les processus sous-tendant les effets d'exposition aux standards de beauté inatteignables et leur régulation restent peu compris. Dans ce contexte, la présente étude examine l'impact d'une telle exposition sur le contrôle inhibiteur. Entre deux blocs d'une tâche de Stroop sémantique, soixante-douze jeunes filles sans troubles étaient exposées à des images d'un modèle féminin de beauté très mince (vs. des images contrôle). L'exposition au modèle n'a pas affecté le niveau d'interférence Stroop sémantique. Néanmoins, l'interférence Stroop standard (qui implique une composante de contrôle inhibiteur) a augmenté dans le second bloc pour les participantes contrôle, alors que les participantes exposées au modèle de beauté parvenaient à maintenir le même niveau d'interférence standard à travers les deux blocs. Ces résultats suggèrent que la comparaison ascendante avec un standard de beauté irréaliste facilite le déploiement du contrôle inhibiteur dans le temps. La discussion se focalise sur le rôle potentiel de la motivation à éviter un état aversif de conscience de soi et les émotions négatives associées dans ces effets, ainsi que sur leurs implications pratiques.

Mots-clés : contrôle inhibiteur, interférence Stroop, standards de beauté, comparison social, théorie de l'évasion 


\section{The Impact of Exposure to Unrealistically High Beauty Standards on Inhibitory Control}

As early as the age of five, girls playing shortly with a Barbie doll - a prime example of unrealistically high beauty standards - experience a decrease in self-esteem and a greater desire to be thin, compared to girls playing with a more realistic doll or other toys (Dittmar, Halliwell, \& Ive, 2006). Later in life, exposure to unrealistically high beauty standards continues through mass media (Groesz, Levine \& Murnen, 2002; Stice, Schupak-Neuberg, Shaw, \& Stein, 1994; Stice, Spangler, \& Agras, 2001) that abound with airbrushed images of top models (Slater, Tiggemann, Firth, \& Hawkins, 2012). Again, this decreases women's self-esteem (Thornton \& Maurice, 1997), and increases body dissatisfaction (e.g., Culbert, Racine \& Klump, 2015; Dittmar, 2009; Grabe, Ward, \& Hyde, 2008; Groesz et al., 2002; Levine \& Murnen, 2009). It further increases the accessibility of suicide-related concepts (especially in body dissatisfied women, Chatard \& Selimbegović, 2011), anxiety (Thornton \& Maurice, 1997), anger (Pinhas, Toner, Ali, Garfinkel, \& Stuckless, 1999) and depressive symptoms (Pinhas et al., 1999; Stice \& Bearman, 2001). Importantly, it also leads to dieting (Stice \& al., 1994; Thomsen, Weber, \& Beth Brown, 2002) and is associated with eating disorders (Harrison \& Cantor, 1997; Stice, 2001).

In sum, exposure to unrealistically high beauty standards produces negative self-relevant emotions, cognitions, and behaviors. Although these self-relevant harmful consequences are well documented, cognitive processes underlying these consequences as well as their regulation still remain poorly understood. By examining the extent to which exposure to unrealistically high beauty standards influences executive inhibitory control, the study reported in this paper addresses just this issue. Indeed, executive inhibitory control is a general-purpose control process that is known to regulate a large variety of one's thoughts and behaviors both in children and adolescents (Diamond, 2013) and in adults (Miyake \& Friedman, 2012). Therefore, it remains highly plausible that is also subtends the effective regulation (or the lack of thereof) of various consequences outlined above. 


\section{EXPOSURE TO BEAUTY STANDARDS AND INHIBITORY CONTROL}

Our general hypothesis is rather straightforward: exposure to unrealistically high beauty standards influences inhibitory control, as measured by a Stroop task. We do not a priori hypothesize a specific direction of this influence, because opposite predictions can be made on the basis of the literature. On one hand, exposure to unrealistically high beauty standards elicits negative self-related cognitions and emotions that might produce a cognitive overload. Indeed, the so-called "chocking under pressure" literature for instance, has amply documented that self-related negative thoughts lead to a cognitive overload that it is associated with reduced executive (task)

control (Belletier, Davranche, Tellier, Dumas, Vidal, Hasbroucq, \& Huguet, 2015; Beilock, 2010, Beilock \& Carr, 2005). Following this line of research, it is likely that an exposure to unrealistically high beauty standards results in a decrease in inhibitory control in the Stroop task. On the other hand, in light of Escape theory (Baumeister, 1991; Chatard \& Selimbegović, 2011), a more efficient maintenance of inhibitory control across time seem equally plausible. Indeed, this theory - focusing specifically on motivational regulation - predicts that a failure to meet high standards induces a motivation to avoid aversive self-awareness and negative emotions. In line with this prediction is the fact that the exposure to unrealistically high beauty standards specifically, increases the accessibility of escape-related thoughts (at least in women that have preexisting body dissatisfaction, Chatard \& Selimbegović, 2011, Experiment 6). Given that sustained attention to the task at hand may relieve individuals from negative affective states (Van Dillen \& Koole, 2007), it is equally likely that an exposure to unrealistically high beauty standards results in a greater maintenance of inhibitory control in the Stroop task (Augustinova, Silvert, Spatola \& Ferrand, 2018; De Jong, Berendsen, \& Cools, 1999). Indeed, De Jong and colleagues (1999) where the first to argue that the poor performance in the Stroop task does not necessarily reflect genuine limitations in people's inhibitory capabilities, but rather certain limitations in the ability to deploy these capabilities consistently across time. More precisely, and in line with the idea of sustained attention to the task emphasized above, these authors argued that this deployment is 


\section{EXPOSURE TO BEAUTY STANDARDS AND INHIBITORY CONTROL}

more consistent as the individuals' attentional focus is intently maintained on the relevant colordimension of Stroop words.

\section{The Present Study}

The aforementioned competing hypotheses were assessed in the so-called semantic Stroop task (e.g., Augustinova \& Ferrand, 2014) in which participants are required to identify the color of the display as quickly and as accurately possible. It supplements the standard color-incongruent (e.g., "BLUE" displayed in green, hereafter $B L U E_{\text {green }}$ ) and color-neutral (e.g., "DEAL" displayed in green, hereafter $\left.D E A L_{\text {green }}\right)$ words commonly used in the standard Stroop task (Stroop, 1935) with associated color-incongruent words (e.g., "SKY" displayed in green, hereafter $S K Y_{\text {green }}$ ).

This addition is rooted in the idea that the standard (i.e., overall) Stroop interference corresponding to faster color-identification latencies for color-incongruent than for color-neutral items ( $\left.B L U E_{\text {green }}-D E A L_{\text {green }}\right)$ results from at least two distinct sources: semantic and response conflicts (e.g., Augustinova et al., 2018; De Houwer, 2003).The semantic conflict arises in the amodal semantic network because the involuntary (i.e., automatic) processing of the worddimension of color-incongruent words (i.e., blue for both $B L U E_{\text {green }}$ and $S K Y_{\text {green }}$ ) interferes with the processing of their color-dimension (i.e., green here). For standard color-incongruent words (e.g., $B L U E_{\text {green }}$ ), the additional source of conflict arises at the response level - the most likely both at the level of response preparation and output. This is because once their meaning has been adequately processed, the color- and word-dimensions of these words prime conflicting (i.e., overlapping) (pre)motor responses (e.g., De Houwer, 2003; Schmidt \& Cheesman, 2005). However, because the word-dimension of associated color-incongruent words (e.g., $S K Y_{\text {green }}$ ) does not activate (incorrect) motor responses linked to the associated color (i.e., press a blue button on seeing SKY; see Schmidt \& Cheesman, 2005 for a direct demonstration), their response set does not overlap with that activated by the color-dimension (e.g. De Houwer, 2003). Hence, associated 


\section{EXPOSURE TO BEAUTY STANDARDS AND INHIBITORY CONTROL}

color-incongruent words (e.g., $S K Y_{\text {green }}$ ) are, exactly like color-neutral ones (e.g., $D E A L_{\text {green }}$ ), free of response conflict.

Consequently, the semantic Stroop interference (i.e., positive difference in mean response latencies between color-associated and color-neutral trials, $\left.S K Y_{\text {green }}-D E A L_{\text {green }}\right)$ is entirely produced by the so-called semantic conflict. Given that this conflict mobilizes automatic semantic processing, the magnitude of semantic Stroop interference remains unchanged by a) various task and/or contextual interventions that are known to modulate the magnitude of standard (i.e., overall) Stroop interference (see Augustinova \& Ferrand, 2014 for a review) and b) healthy aging (Augustinova, Clarys, Spatola, \& Ferrand, 2018).

The standard Stroop interference $\left(B L U E_{\text {green }}-D E A L_{\text {green }}\right)$, on the other hand, results from a joint contribution of both semantic and so-called response conflict. Given that this latter conflict mobilizes executive inhibitory control, the magnitude of overall (i.e., standard) Stroop interference varies as a function of both task and/or contextual interventions and healthy aging mentioned above. However, these variations in magnitudes of overall (i.e., standard) Stroop interference are precisely due to changes in the contribution of (controllable) response conflict and not to changes in the one of (automatic) semantic conflict (see Augustinova et al., 2018; Augustinova \& Ferrand, 2014 for a review).

Given that high beauty standards are expected to specifically influence the executive inhibitory control, we a priori predicted this influence to be seen in the standard (as opposed to semantic) Stroop interference.

\section{Method}

\section{Participants}

Seventy-two French female students $\left(M_{a g e}=19.81\right.$ years, $\left.S D=1.51\right)$ took part in the study and received course credit for their participation. All were native French speakers, had normal or corrected-to-normal vision, and were not color-blind. According to their computed BMI $(M=$ 


\section{EXPOSURE TO BEAUTY STANDARDS AND INHIBITORY CONTROL}

21.92, $S D=4.62), 63.9 \%$ of these participants had normal weight, $19.4 \%$ were underweight, $12.5 \%$ were overweight, and $4.2 \%$ were obese.

\section{Power analysis}

Based on sample size and the observed correlation between the two measurements of standard Stroop interference (before and after exposure, $r(72)=.32$ ), achieved power to detect a medium-sized $(d=0.42)$ within-between interaction effect with an alpha level of .05 was adequate, $1-\beta=.85$. We used $d=0.42$ in this analysis, since this is the mean effect size found in social psychology experiments (Richard, Bond, \& Stokes-Zoota, 2003).

\section{Design and Stimuli}

The data from the Stroop task was collected using a 4 (Stimulus Type: standard vs. associated color-incongruent words vs. their respective color-neutral counterparts) $\times 2$ (Experimental Block: before vs. after exposure) $\times 2$ (Images: beauty standards $v s$. control) design, with the last factor being manipulated between participants. There were 24 trials for each Stimulus Type factor condition, which varied randomly within two blocks of the 96 analyzed trials ${ }^{1}$.

The stimuli (taken from Augustinova et al., 2017, and presented in lowercase Courier font, size 18 , on a black background subtending an average visual angle of $0.9^{\circ}$ high $\times 3.0^{\circ}$ wide) consisted of four color-words: rouge [red], jaune [yellow], bleu [blue], and vert [green]; four color-neutral words that matched the color-words in length and frequency: page [page], plomb [lead], liste [list] and cave [cellar]; four color-associated words: tomate [tomato], maïs [corn], ciel [sky], and salade [salad]; and four of their matching counterparts: fête [party], écho [echo], indice [clue] and fusion [molten]. Color-incongruent and color-associated words always appeared in colors that were incongruent with their meaning.

\section{Procedure and Materials}

\footnotetext{
${ }^{1}$ In reality, each block consisted of 144 trials because 48 additional items consisting of strings of Xs were added to decrease the proportion of color-incongruent trials and to heighten their interfering effect that is under scrutiny in this paper. Indeed, the standard Stroop interference is known to increase as the proportion of incongruent trials decreases (Tzelgov, Henik, \& Berger, 1992).
} 


\section{EXPOSURE TO BEAUTY STANDARDS AND INHIBITORY CONTROL}

Participants were tested individually. They first completed a computerized version of the Stroop task. E-Prime 2.0 run on a PC was used for stimulus presentation and data collection. Participants were seated approximately $50 \mathrm{~cm}$ from a 17 -inch screen. They were told that their task was to identify out loud the color of letter strings presented on the screen, as quickly and accurately as possible, while ignoring their meanings. At the beginning of each trial, a white fixation cross (“+”) appeared in the center of the (black) screen. After $500 \mathrm{~ms}$, it was replaced by the stimulus, which was displayed until response or for 2000ms. Participants' vocal responses were recorded via a Philips SBC ME570 microphone and stored on a SONY ISDPX333 recorder.

After completing 16 practice trials (MacLeod, 2005) consisting of strings of asterisks (presented in the four colors described above), participants performed the experimental task, which consisted of two blocks of 96 experimental trials (starting with 12 void trials) and a break between the blocks.

During this break, participants were asked to take part in another presumed study in consumer psychology, administered on a different computer using E-Prime 2.0. All participants agreed, and were randomly assigned to one of the two conditions described below. In the beauty standard condition $(N=36)$, participants first reported their height and weight. They next completed the 9-item Body Dissatisfaction Scale (BDS; Garner, Olmsted, \& Polivy, 1983, e.g., «I think that my hips are too big », $\alpha=.87)$. Participants indicated their agreement with each statement at the moment on 7-point Likert scales $(1=\ll$ completely disagree $» ; 7=$ «completely agree »). High scores indicated high body dissatisfaction. Completing this scale attracted participants' attention to their body shape and served to activate an evaluative mindset in relation to physical appearance. They were then exposed to three pictures of the same female model wearing three different sets of underwear in three different positions (10 seconds each; see Appendix), and instructed to choose the picture that they preferred. 


\section{EXPOSURE TO BEAUTY STANDARDS AND INHIBITORY CONTROL}

The stimuli were three photographs of Rachel Stevens, a pop singer and a model, issued from the Rachel Stevens Official Calendar 2010. We used photographs for January, March, and May. The original photographs have airbrushed in order to make the model extremely thin in the experimental condition, and to display underwear only (without the body) in the control condition. We believe that it can be safely assumed that the photographs for the 2010 Calendar were shot in 2009. As Rachel Stevens was born in April 1978, she was 21 years old in 2009. The mean age in our sample was just below 20. Therefore, the model was approximately of the same age as the participants. The model also appeared to be of the same ethnic type as the majority of participants (Caucasian), although we did not collect information about participants' ethnicity, because this is considered as socially undesirable in the French society.

In the object (control) condition $(N=36)$, participants first answered a filler questionnaire containing nine items about consumer choices (e.g. «I think there are too many Chinese products on the market »). They were then exposed to three control pictures (under the same instructions to choose the one that they preferred), constructed by modifying the images used in the experimental condition to erase the model's body and keep only the underwear in the picture (Appendix). Thus, in this condition participants' attention was less focused on their body image and they had little reason to compare and evaluate their physical appearance to that of a fashion model, because only underwear was visible. The questions about participants' height and weight and the BDS were completed after the second block of the Stroop task.

\section{Results}

\section{Preliminary Analyses: Baseline Differences}

To ensure that there were no detectable initial differences between participants in the beauty standard and the control condition, we submitted baseline (i.e., Block 1) standard and semantic Stroop interference, in BMI level, or in body dissatisfaction to an independent sample t test. Results indicated that there were no baseline differences between conditions on any of these 


\section{EXPOSURE TO BEAUTY STANDARDS AND INHIBITORY CONTROL}

indicators (Table I). Therefore, there is no reason to believe that a sampling bias might influence the findings.

Table I. Baseline Stroop performance, Body Mass Index, and Body dissatisfaction as a function of condition

\begin{tabular}{lccccc}
\hline & $\begin{array}{c}\text { Control } \\
\text { condition } \\
M(S D)\end{array}$ & $\begin{array}{c}\text { Beauty } \\
\text { standard } \\
\text { condition } \\
M(S D)\end{array}$ & $\mathrm{t}(70)$ & $\mathrm{p}$ & $\eta^{2}$ \\
\hline Stroop block 1 - standard & $13.01(12.07)$ & $14.29(9.71)$ & -0.50 & .62 & .004 \\
Stroop block 1 - semantic & $1.74(6.03)$ & $3.27(5.17)$ & -1.15 & .25 & .019 \\
Body Mass Index & $22.45(5.46)$ & $21.39(3.58)$ & 0.97 & .33 & .013 \\
Body dissatisfaction & $3.74(1.11)$ & $3.71(1.14)$ & 0.12 & .91 & $<.001$ \\
\hline
\end{tabular}

\section{Main Results: Semantic and Standard Stroop Interference}

In order to control for overall processing speed that varies importantly with task repetition (i.e., block 1 vs. block 2) but also across participants and to neutralize potential differences in processing of the two color-neutral baselines, we computed percentages of standard ([( $\mathrm{M}_{\text {standard }}$ color-incongruent RT $\left.\left.\left.-\mathrm{M}_{\text {color-neutral RT }}\right) / \mathrm{M}_{\text {color-neutral RT }}\right] * 100\right)$ and semantic Stroop interference ([( $\mathrm{M}_{\text {color- }}$ associated incongruent RT $-\mathrm{M}_{\text {color-neutral RT) }} \mathrm{M}_{\text {color-neutral RT] }}$ * 100; Augustinova et al., 2018; Li \& Bosman, 1996).

Percentage of both standard and semantic interference was submitted to a 2 (Experimental Block: before/Block 1 vs. after exposure/Block 2$) \times 2$ (Experimental condition: beauty standards vs. control) mixed ANOVA in order to examine the influence of exposure to unrealistically high beauty standards on inhibitory control (for means and standards deviations, see Table II).

In line with our a priori prediction about the involvement of inhibitory control, the percentages of semantic Stroop interference remained unaffected by our manipulation ${ }^{2}$. Indeed,

\footnotetext{
2 The significance of both standard and semantic interference results was unchanged when body dissatisfaction was controlled for.
} 


\section{EXPOSURE TO BEAUTY STANDARDS AND INHIBITORY CONTROL}

after screening the percentage of semantic Stroop interference data for outliers ${ }^{3}$, the block by condition interaction was not significant, $F(1,69)=1.29, p=.26, \eta_{p}^{2}=.02$. Main effects of block and condition were not significant either, $F(1,69)=1.04, p=.31, \eta_{p}^{2}=.02$, and $F(1,69)=0.15, p$ $=.70, \eta_{p}^{2}=.002$, respectively. In short, these analyses suggest that both groups maintained the same level of semantic Stroop interference (addressing semantic processing) across the two blocks of the Stroop task.

After screening the percentage of standard Stroop interference data for outliers and discarding three participants from the analysis $(z>3)^{4}$, main effects of block and condition were non significant, $F(1,67)=3.36, p=.07, \eta^{2}{ }_{p}=.05$, and $F(1,67)=0.02, p=.90, \eta^{2}<.001$, respectively. However, the analysis yielded a significant interaction $F(1,67)=8.26, p=.005, \eta^{2} \mathrm{p}=$

.11 (Figure 1). To perform Bayesian analysis, we submitted the difference score in standard Stroop interference to a Bayesian independent samples t test, which corresponds to testing the Block by Condition interaction. We used the default Bayesian approach $($ Cauchy prior $=0.707)$, because we had no a priori assumptions about effect size (Gönen, Johnson, Lu, \& Westfall, 2005). Results that indicated the interaction hypothesis is 7.54 times more likely to be true than the null hypothesis of an absence of the interaction $\left(\mathrm{BF}_{01}=7.54\right)$, which represents substantial evidence in favour of the interaction hypothesis, according to Jeffreys (1961).

Figure 1. Percentage of standard Stroop interference as a function of exposure condition and experimental block

\footnotetext{
3 One participant in the beauty standards condition had an extreme score in Block $2(\mathrm{z}=3.09)$ and was thus discarded from the analysis.

${ }^{4}$ Two participants in the control condition had extreme scores in Block $1(\mathrm{z}=3.36$ and $\mathrm{z}=3.13)$, and one participant in the beauty standard condition had an extreme score in Block $2(\mathrm{z}=4.55)$.
} 
Figure 1. Percentage of standard Stroop interference as a function of exposure condition and experimental block

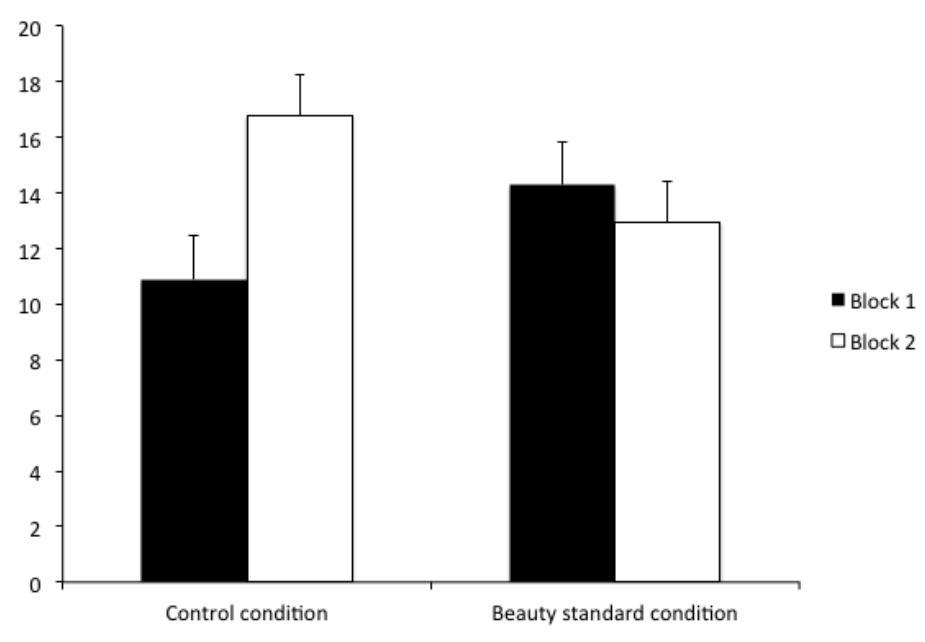

Figure 1. Percentage of standard Stroop interference as a function of exposure condition and experimental block

To better understand this interaction, we tested the effects of experimental block within each experimental condition. There was a significant effect of experimental block in the control condition, $t(67)=3.30, p=.002$, showing that standard interference increased from Block 1 (before exposure, $M=10.89, S D=8.45$ ) to Block 2 (after exposure, $M=16.79, S D=8.87$ ). However, in line with the idea that exposure to unrealistic beauty standards can contribute to sustain inhibitory control, performance after exposure to idealized beauty pictures $(M=12.97, S D$ $=8.13)$ was comparable to performance before exposure $(M=14.27, S D=9.85), t(67)=-0.74, p$ $=.46$. 


\section{EXPOSURE TO BEAUTY STANDARDS AND INHIBITORY CONTROL}

Table II. Means and standard deviations for each type of trial, each block, and each condition, without the outliers

\begin{tabular}{lcccc}
\hline & \multicolumn{2}{c}{ Block 1 } & \multicolumn{2}{c}{ Block 2 } \\
\hline & $\begin{array}{c}\text { Control } \\
\text { condition } \\
M(S D)\end{array}$ & $\begin{array}{c}\text { Beauty standard } \\
\text { condition } \\
M(S D)\end{array}$ & $\begin{array}{c}\text { Control } \\
\text { condition } \\
M(S D)\end{array}$ & $\begin{array}{c}\text { Beauty standard } \\
\text { condition } \\
M(S D)\end{array}$ \\
\hline $\begin{array}{l}\text { Standard color- } \\
\text { incongruent trials }\end{array}$ & 778.77 & 812.93 & 843.33 & 838.70 \\
& $(113.87)$ & $(142.10)$ & $(144.00)$ & $(155.22)$ \\
$\begin{array}{l}\text { Semantic color- } \\
\text { incongruent trials }\end{array}$ & 712.08 & 733.54 & 749.70 & 750.14 \\
$\begin{array}{l}\text { Color-neutral } \\
\text { standard }\end{array}$ & $(95.63)$ & $(99.28)$ & $(109.65)$ & $(124.40)$ \\
counterparts & 702.08 & 708.53 & 723.01 & 742.48 \\
$\begin{array}{l}\text { Color-neutral } \\
\text { semantic } \\
\text { counterparts }\end{array}$ & $(80.24)$ & $(84.50)$ & $(116.81)$ & $(126.92)$ \\
& 701.17 & 709.32 & 727.39 & 720.33 \\
\hline
\end{tabular}

\section{Complementary analyses: Mental Fatigue ${ }^{5}$}

To examine whether mental fatigue occurred from Block 1 to Block 2, we analyzed two indicators: mean reaction time across all trials (irrespective of trial type), and mean reaction time variability across all trials. Reaction time variability was assessed by the standard deviation of reaction times calculated for each individual. If mental fatigue increased from Block 1 to Block 2, then mean reaction time and/or mean reaction time variability should be higher in Block 2 as compared to Block 1 (Boksem, Meijman, \& Lorist, 2006; Kato, Endo, \& Kizuka, 2009; Rauch \& Schmitt, 2009). Mean reaction time and mean reaction time variability were submitted to a 2 (Experimental Block: before/Block 1 vs. after exposure/Block 2) $\times 2$ (Experimental condition: beauty standards $v s$. control) mixed ANOVA. On mean reaction time, only a significant effect of Experimental Block was revealed, such that reaction times were longer in Block $2(M=742.53$, $S D=114.17)$, than in Block $1(M=718.45, S D=89.94), F(1,70)=12.41, p=.001, \eta^{2}{ }_{p}=.15$. On

\footnotetext{
${ }^{5}$ We thank an anonymous reviewer for suggesting these complementary analyses.
} 


\section{EXPOSURE TO BEAUTY STANDARDS AND INHIBITORY CONTROL}

mean reaction time variability, the same pattern emerged: only a significant effect of Experimental Block was revealed, such that reaction time variability was larger in Block $2(M=160.97, S D=$ 71.60), than in Block $1(M=143.96, S D=59.80), F(1,70)=8.42, p=.005, \eta^{2}{ }_{p}=.11 .^{6}$

Therefore, participants in both conditions seem to have experienced mental fatigue that as expected - is associated with the repetition of resources-demanding Stroop task. Yet it is important to remember at this point that only participants in control condition experienced concomitantly a significant drop in the magnitude of standard Stroop inference (addressing semantic processing and inhibitory control). Thus, the absence of this same drop in participants exposed to high beauty standards along with the same level of semantic Stroop interference (addressing semantic processing) in both groups reinforces the idea that these participants were indeed more efficient in the deployment of inhibitory control across time of the task (De Jong et al., 1999).

\section{Discussion}

The consequences for young women of exposure to images of idealized female beauty on self-relevant, explicit emotions and cognition, as well as certain behaviors are well-documented. Nevertheless, the extant literature provides little insight about cognitive processes that are likely to subtend these consequences and their regulation. The present study aimed to bring a contribution in this regard by examining the influence of exposure to unrealistically high beauty standards on executive inhibitory control.

To this end, we used a within-between experimental design, in which participants completed a semantic Stroop task before and after being exposed either to a picture of idealized

\footnotetext{
6 Main effects of Experimental Condition and the Condition by Block interaction were not significant for mean reaction time, $F(1,70)=0.17, p=.68, \eta_{p}^{2}=.002$, and $F(1,70)=0.49, p=.49, \eta_{p}^{2}=.007$, respectively, or for mean reaction time variability, $F(1,70)=0.05, p=.83, \eta_{\mathrm{p}}^{2}=.001$, and $F(1,70)=0.65, p=.42, \eta_{\mathrm{p}}^{2}=.009$, respectively.
} 


\section{EXPOSURE TO BEAUTY STANDARDS AND INHIBITORY CONTROL}

beauty or to a picture of underwear (without the body). This within-participants experimental design allowed us to increase power and have less error variance (as compared to an equivalent between-participants design with the same sample size), as each participant acted as her own control/baseline. In addition, in this way we were able to track changes in inhibitory control in a dynamic way, and look how the magnitude of standard (as compared to semantic) Stroop interference evolved within the same individual.

Also, and importantly, the distinction between semantic and standard Stroop interference allowed us to ensure that the executive inhibitory control per se (as opposed to other processes involved in the overall Stroop interference, see e.g. Augustinova \& Ferrand, 2014) is impacted by the exposure to high beauty standards. This is indeed the case as suggested by the a priori expected effect of our exposure manipulation on the magnitude of standard (as opposed to semantic) Stroop interference.

It should be remembered at this point that the direction of this effect was not specified a priori because opposite predictions could be made on the basis of previous research. Following "chocking under pressure" research, an exposure to unrealistically high beauty standards (and negative self-relevant thoughts that it entails) could have resulted in a decrease in executive inhibitory control in the Stroop task. This is clearly not the case as a larger magnitude of standard Stroop interference was precisely observed after exposure to control images.

The fact that this magnitude remained unchanged across the time of the task in the beauty standard condition is rather consistent with our alternative prediction that the social comparison with an unrealistically high beauty standard might result in a greater efficiency in the deployment of inhibitory control across time of the task (De Jong et al., 1999).

Recall that this more efficient deployment is commonly attributed to a greater maintenance of the individuals' attentional focus on the relevant color-dimension of Stroop words across time of the task (De Jong et al., 1999; Jackson \& Balota, 2013). This lower-level cognitive 


\section{EXPOSURE TO BEAUTY STANDARDS AND INHIBITORY CONTROL}

interpretation is actually consistent with Escape theory predicting that the motivation to escape negative self-awareness results in a more sustained attention to the task (Baumeister, 1991;

Chatard \& Selimbegović, 2011). In this way, the focus of attention switches from internal (selffocus) to external (task at hand), and benefits the deployment of inhibitory control in the Stroop task.

Even though we don't have any direct evidence in favor of this latter kind of motivation per se, the involvement of motivation is reinforced by the fact that the inhibitory maintenance occurred only among participants exposed to high beauty standards whereas all participants actually experienced mental fatigue (as indicated by elevated response times and response time variability in Block 2 as compared to Block 1). Overcoming obstacles (such as fatigue and/or boredom associated to the task) is indeed an important indicator of motivation (Bargh, Lee-Chai, Barndollar, Gollwitzer, \& Trötschel, 2001).

To conclude, in light of specific pattern of our results depicted above and given that negative thoughts and escape-related cognitions are known to become more accessible upon thin ideal exposure (Chatard \& Selimbegović, 2011), we are inclined to identify the motivation to escape aversive self-awareness as a prime motivational mechanism driving our result. Yet, for this interpretation to be granted, other studies addressing its direct implication in a greater deployment of executive inhibitory control - clearly observed in the present study - are necessary. Additionally, demonstrating a moderating role of the avoidant coping might corroborate further the interpretation in terms of escape motivation. Indeed, Chatard and Selimbegović (2011, Experiment 1) reported this moderation effect, such that high avoidant coping facilitated the increase in suicide-related thought accessibility after failure priming. If the escape account that we are inclined to favor is correct, then only tasks that allow distraction from the self (e.g., the Stroop task using color- and color-associated words used in the present study) should benefit from a performance boost. In contrast, tasks that foster self-focus (e.g., the Stroop task using body and/or 


\section{EXPOSURE TO BEAUTY STANDARDS AND INHIBITORY CONTROL}

appearance-associated words as distractor, e.g., Long, Hinton, \& Gillespie, 1994) should show performance drops, because participants with feelings of failure should be reluctant to engage in such tasks.

\section{Limitations and future research}

Along with the aforementioned, perhaps the most important limitation due to the lack of direct support for the interpretation in term of Escape Theory, other limitations are worth mentioning. Indeed, they represent additional venues for future research. First, we intentionally confounded exposure unrealistically high beauty standards and exposure to the body dissatisfaction scale (and height/weight questions), in order to create a comparative and evaluative context in the experimental condition, and a comparison- and evaluation-free context in the control condition. This entails an ambiguity in interpreting the results, because we cannot know whether the effect of the manipulation was due to exposure to questions about body selfperception, or to exposure to the pictures of idealized beauty. However, the findings are consistent with the more general idea that raising concerns about one's appearance facilitates inhibitory control. Future research is needed to disentangle effects of exposure to questions about appearance and of exposure to unrealistically high beauty standards.

Second, in addition to explanation of the present findings in term of Escape Theory that we are inclined to favor, other possible explanations may be taken into consideration. One possibility is that women exposed to idealized beauty, who felt that they have failed to reach this cultural standard of physical appearance, tried harder in the subsequent Stroop task because they strived to restore their self-esteem by performing well on this different, cognitive task. Brunstein and Gollwitzer (1996) have explored the consequences of failure in a domain important for selfdefinition on subsequent performance. Their results suggest that after failure, performance in the same, self-definitional domain increases, but performance in an unrelated domain decreases. Thus, if physical appearance is important in the self-definition of young women from our sample, then 


\section{EXPOSURE TO BEAUTY STANDARDS AND INHIBITORY CONTROL}

their performance in an unrelated cognitive domain would be expected to suffer from failure to attain a standard of beauty, contrary to what our results show. However, as we did not assess the importance of physical appearance for self-esteem in our sample, future research may investigate this variable as a possible moderator of the reported effects.

At the same time, maintaining or restoring self-esteem can be achieved not only by excelling in the task at hand but also by avoiding the painful implications of the upward social comparison for the self. From this viewpoint, the present results can be interpreted as consistent with both the Escape theory (Baumeister, 1991) and a general theoretical framework related to self-regulation, namely the identity-value model (Berkman, Livingston, \& Kahn, 2017). In this perspective, self-regulation is governed by perceived value of a given behavior in confirming or enhancing one's globally positively valued identity. Also, the goal of maintaining a positive selfimage is acknowledged as a fundamental human motivation. When this positive identity is threatened, a person can either disengage from the goal, increase identification with the goal, or engage in self-handicapping (Berkman et al., 2017). In the context of the present study, participants were threatened on the dimension of physical appearance by being exposed to an unattainable standard. There was nothing in the immediate situation that they could do to close the gap between their actual selves and the standard. Therefore, the best that they could do to preserve self-esteem and therefore their identity, was to disengage from thoughts about physical appearance and the unfavorable comparison, and direct their attention instead to the task at hand requiring inhibitory control. It is quite possible that if they had the opportunity to choose a behavior likely to bring them closer to the salient goal of physical attractiveness, they would have chosen that behavior, rather than an escapist one (although this is questionable in the case of an unattainable standard). Future research might endeavor to directly test this alternative explanation that might potentially have important implications for long-term behavioral consequences of exposure to high beauty standards. 


\section{EXPOSURE TO BEAUTY STANDARDS AND INHIBITORY CONTROL}

\section{Summary, conclusions and practical implications}

The present study demonstrated that raising appearance concerns in young women results in greater maintenance of executive inhibitory control in a Stroop task. On the basis of complementary results - namely those addressing the issue of mental fatigue - it is argued that this greater maintenance of executive inhibitory control me can be accounted for by a motivational mechanism. Although additional and more direct data are necessary, we are inclined to conclude that this motivational mechanism corresponds precisely to the motivation to escape negative selfawareness resulting from social comparison with a high standard of beauty exemplified by the thin ideal.

Thus, at least three main contributions of the present findings to the extant literature deserve to be underlined. First, to our knowledge, this is the first time that effects of exposure to unrealistically high beauty standards were explored on self-unrelated cognitive processing. Second, the present research opens up the important question of the impact of social comparison on executive inhibitory control - general purpose mechanism that is likely to be involved in the effective regulation (or the lack of thereof) of various negative consequences of this exposure. Thus, third, these findings might potential complement Baumeister's (1991) escape theory by showing by incorporating this latter aspect that was previously unstudied in this theoretical framework.

The findings reported in the present study also have potential practical implications namely in relation to control of eating behavior. Indeed, an interesting yet remaining question is whether a more consistent deployment of inhibitory control demonstrated in this study can actually impact this type of behavior and how. Lowe, Kolev, and Hall (2016) have shown that a boost in cognitive inhibitory control (induced by aerobic exercise and measured in a Stroop task) mediated an increase in behavioural inhibitory control in a tasting task (on caloric snacks but not on control food). Consistent with the idea that failure increases inhibitory control, Heatherton, Polivy, 


\section{EXPOSURE TO BEAUTY STANDARDS AND INHIBITORY CONTROL}

Herman, and Baumeister (1993) showed that restrained eaters (i.e. participants who were on a diet) ate less after viewing a video of themselves failing on a task (failure/high self-awareness condition) than restrained eaters in a neutral video and a no video conditions.

However, there is also research suggesting that feeling threatened in relation to one's physical appearance increases caloric snacks consumption among individuals stigmatized for their weight (Major, Hunger, Bunyan, \& Miller, 2014). Similarly, it has been argued that failure and the ensuing aversive self-awareness diminish inhibitory control, and that binge eating can thus result from a desire to escape negative self-awareness (Heatherton \& Baumeister, 1991). In sum, results are mixed as to how failure in general, and failure and threat to self-image in relation to body size specifically, affect behavioural inhibitory control. Further research might endeavour to specify the conditions in which behavioural inhibitory control is boosted versus released by investigating diverse populations (overweight/obese, restrained eaters, normal weight), and diverse types of failure and threat. In order to further develop these explanations that have obvious social and public health implications, future research might include eating choice and/or calorie consumption measures in additional to relevant and reliable measures of inhibitory control (see e.g., Augustinova et al., 2016 in this outlet). 


\section{EXPOSURE TO BEAUTY STANDARDS AND INHIBITORY CONTROL}

\section{References}

Augustinova, M., \& Ferrand, L. (2012). The influence of mere social presence on Stroop interference: New evidence from the semantically-based Stroop task. Journal of Experimental Social Psychology, 48, 1213-1216. doi: 10.1016/j.jesp.2012.04.014

Augustinova, M., \& Ferrand, L. (2014). Automaticity of word reading: Evidence from the semantic Stroop paradigm. Current Directions in Psychological Science, 23, 343-348. doi: $10.1177 / 0963721414540169$

Augustinova, M., Silvert, L., Spatola, N., \& Ferrand, L. (2018). Further investigation of distinct components of Stroop interference and of their reduction by short response-stimulus intervals. Acta Psychologica, 189, 54-62. doi: 10.1016/j.actpsy.2017.03.009

Augustinova, M., Almeida, E., Clarys, D., Ferrand, L., Izaute, M., Jalenques, I., Juneau, C., Normand, A., \& Silvert, L. (2016). What the Stroop interference actually measures? When and how? Methodological and theoretical arguments in favor of change in its measurement. L'Année Psychologique/Topics in Cognitive Psychology, 116, 45-66. doi: $10.4074 / \mathrm{S} 000350331500024 \mathrm{X}$

Bargh, J. A., Gollwitzer, P. M., Lee-Chai, A., Barndollar, K., \& Trötschel, R. (2001). The automated will: Nonconscious activation and pursuit of behavioral goals. Journal of Personality and Social Psychology, 81, 1014-1027. doi: 10.1037//0022-3514.81.6.1014

Baumeister, R. F. (1991). Escaping the Self: Alcoholism, Spirituality, and Other Flights from the Burden of Selfhood. New York: Basic Books.

Beilock, S. (2010). Choke: What the secrets of the brain reveal about getting it right when you have to. New York: Free Press.

Beilock, S. L., \& Carr, T. H. (2005). When high-powered people fail working memory and “choking under pressure" in math. Psychological Science, 16, 101-105. doi: 10.1111/j.0956-7976.2005.00789.x 


\section{EXPOSURE TO BEAUTY STANDARDS AND INHIBITORY CONTROL}

Belletier, C., Davranche, K., Tellier, I. S., Dumas, F., Vidal, F., Hasbroucq, T., \& Huguet, P. (2015). Choking under monitoring pressure: being watched by the experimenter reduces executive attention. Psychonomic Bulletin \& Review, 22, 1410-1416. doi:

10.1016/j.biopsycho.2005.08.007

Berkman, E. T., Livingston, J. L., \& Kahn, L. E. (2017). Finding the "self" in self-regulation: The identity-value model. Psychological Inquiry, 28, 77-98. doi : 10.1080/1047840X.2017.1323463

Boksem, M. A., Meijman, T. F., \& Lorist, M. M. (2006). Mental fatigue, motivation and action monitoring. Biological Psychology, 72, 123-132.

Brunstein, J. C., \& Gollwitzer, P. M. (1996). Effects of failure on subsequent performance: The importance of self-defining goals. Journal of Personality and Social Psychology, 70, 395407. doi: 10.1037/0022-3514.70.2.395

Chatard, A., \& Selimbegović, L. (2011). When self-destructive thoughts flash through the mind: Failure to meet standards affects the accessibility of suicide-related thoughts. Journal of Personality and Social Psychology, 100, 587-605. doi: 10.1037/a0022461

Crandall, C. S., \& Schiffhauer, K. L. (1998). Anti-Fat Prejudice: Beliefs, Values, and American Culture. Obesity Research, 6, 458-460. doi: 10.1002/j.1550-8528.1998.tb00378.x

Culbert, K. M., Racine, S. E., \& Klump, K. L. (2015). Research Review: What we have learned about the causes of eating disorders - A synthesis of sociocultural, psychological, and biological research. Journal of Child Psychology and Psychiatry, 56, 1141-1164. doi: 10.1111/jcpp.12441.

D’agostino, P. R., \& Pittman, T. S. (1982). Effort expenditure following control deprivation. Bulletin of the Psychonomic Society, 19, 282-283. doi: 10.3758/BF03330258

De Houwer, J. (2003). On the role of stimulus-response and stimulus-stimulus compatibility in the Stroop effect. Memory \& Cognition, 31, 353-359. doi: 10.3758/BF03194393 


\section{EXPOSURE TO BEAUTY STANDARDS AND INHIBITORY CONTROL}

De Jong, R., Berendsen, E., \& Cools, R. (1999). Goal neglect and inhibitory limitations: Dissociable causes of interference effects in conflict situations. Acta psychologica, 101, 379-394. doi: 10.1016/S0001-6918(99)00012-8

Diamond, A. (2013). Executive functions. Annual Review of Psychology, 64, 135-168. doi: 10.1146/annurev-psych-113011-143750

Dittmar, H. (2009). How do "body perfect" ideals in the media have a negative impact on body image and behaviors? Factors and processes related to self and identity. Journal of Social and Clinical Psychology, 28, 1-8. doi: 10.1521/jscp.2009.28.1.1

Dittmar, M., Halliwell, E., \& Ive, S. (2006). Does Barbie make girls want to be thin ? The effect of experimental exposure to images of dolls on the body image of 5-to 8-year-old girls. Developmental Psychology, 42, 283-292. doi: 10.1037/0012-1649.42.2.283

Garner, D. M., Olmstead, M. P., \& Polivy, J. (1983). Development and validation of a multidimensional eating disorder inventory for anorexia nervosa and bulimia. International Journal of Eating Disorders, 2, 15-34. doi: 10.1002/1098-108X(198321)2:2<15::AIDEAT2260020203>3.0.CO;2-6

Gönen, M., Johnson, W. O., Lu, Y., \& Westfall, P. H. (2005). The Bayesian two-sample t-test. American Statistician, 59, 252-257. doi : 10.1198/000313005X55233

Grabe, S., Ward, L. M., \& Hyde, J. S. (2008). The role of the media in body image concerns among women: A meta-analysis of experimental and correlational studies. Psychological Bulletin, 134, 460-476. doi: 10.1037/0033-2909.134.3.460

Groesz, L. M., Levine, M. P., \& Murnen, S. K. (2002). The Effect of Experimental Presentation of Thin Media Images on Body Satisfaction: A Meta-Analytic Review. International Journal of Eating Disorders, 31, 1-16. doi : 10.1002/eat.10005 


\section{EXPOSURE TO BEAUTY STANDARDS AND INHIBITORY CONTROL}

Harrison, K., \& Cantor, J. (1997). The relationship between media consumption and eating disorders. Journal of Communication, 47, 40-67. doi: 10.1111/j.14602466.1997.tb02692.x

Heatherton, T. F., Polivy, ., Herman, C. P., \& Baumeister, R. F. (1993). Self-awareness, task failure, and disinhibition: How attentional focus affects eating. Journal of Personality, 61 , 49-61. doi: 10.1111/j.1467-6494.1993.tb00278.x

Kato, Y., Endo, H., \& Kizuka, T. (2009). Mental fatigue and impaired response processes: eventrelated brain potentials in a Go/NoGo task. International Journal of Psychophysiology, 72, 204-211. doi : 10.1016/j.ijpsycho.2008.12.008

Heatherton, T. E, \& Baumeister, R. F. (1991). Binge eating as an escape from self-awareness. Psychological Bulletin, 110, 86-108. doi: 10.1037/0033-2909.110.1.86

Jeffreys, H. (1961). Theory of Probability, 3rd ed. Oxford : Oxford University Press.

Levine, M. P., \& Murnen, S. K. (2009). "Everybody knows that mass media are/are not [pick one] a cause of eating disorders": A critical review of evidence for a causal link between media, negative body image, and disordered eating in females. Journal of Social and Clinical Psychology, 28, 9-42. doi: 10.1521/jscp.2009.28.1.9

Li, K. Z. H., \& Bosman, E. A. (1996). Age differences in Stroop-like interference as a function of semantic relatedness. Aging, Neuropsychology, and Cognition, 3, 272-284. doi: $10.1080 / 13825589608256630$

Long, C. G., Hinton, C., \& Gillespie, N. K. (1994). Selective processing of food and body size words: Application of the Stroop test with obese, restrained eaters, anorexics and normals. International Journal of Eating Disorders, 15, 279-283. doi : 10.1002/1098108X(199404)15:3<279::AID-EAT2260150312>3.0.CO;2-2 


\section{EXPOSURE TO BEAUTY STANDARDS AND INHIBITORY CONTROL}

Lowe, C. J., Kolev, D., \& Hall, P. A. (2016). An exploration of exercise-induced cognitive enhancement and transfer effects to dietary self-control. Brain and Cognition, 110, 102111. doi: 10.1016/j.bandc.2016.04.008

MacLeod, C. M. (2005). The Stroop Task in Cognitive Research. In A. Wenzel \& D. C. Rubin (Eds.), Cognitive methods and their application to clinical research (pp. 17-40). Washington: American Psychological Association.

Major, B., Hunger, J. M., Bunyan, D. P., \& Miller, C. T. (2014). The ironic effects of weight stigma. Journal of Experimental Social Psychology, 51, 74-80. doi: 10.1016/j.jesp.2013.11.009

Miyake, A., \& Friedman, N. P. (2012). The nature and organization of individual differences in executive functions: Four general conclusions. Current Directions in Psychological Science, 21, 8-14. doi: 10.1177/0963721411429458

Pinhas, L., Toner, B. B., Ali, A., Garfinkel, P. E., \& Stuckless, N. (1999). The effects of the ideal of female beauty on mood and body satisfaction. International Journal of Eating Disorders, 25, 223-226.ǐ̌epidoi: 10.1002/(SICI)1098-108X(199903)25:2<223::AIDEAT12>3.0.CO;2-B

Puhl, R., \& Brownell, K. D. (2001). Bias, Discrimination, and Obesity. Obesity Research, 9, 788805. doi: /10.1038/oby.2001.108

Rauch, W. A., \& Schmitt, K. (2009). Fatigue of Cognitive Control in the Stroop-Task. In N. A. Taatgen \& H. van Rijn (eds.), Proceedings of the 31st Annual Conference of the Cognitive Science Society, 750-755.

Ric, F., \& Scharnitzky, P. (2003). Effects of control deprivation on effort expenditure and accuracy performance. European Journal of Social Psychology, 33, 103-118. doi: 10.1002/ejsp. 134 


\section{EXPOSURE TO BEAUTY STANDARDS AND INHIBITORY CONTROL}

Richard, F. D., Bond, C. F. J., \& Stokes-Zoota, J. J. (2003). One Hundred Years of Social Psychology Quantitatively Described. Review of General Psychology, 7, 331-363. doi: 10.1037/1089-2680.7.4.331

Roehling, M. V. (1999). Weight-based discrimination in employment: Psychological and legal aspects. Personnel Psychology, 52, 969-1016. doi: 10.1111/j.1744-6570.1999.tb00186.x

Schmidt, J. R., \& Cheesman, J. (2005). Dissociating Stimulus-Stimulus and Response-Response Effects in the Stroop Task. Canadian Journal of Experimental Psychology/Revue Canadienne de Psychologie Expérimentale, 59, 132-138. doi: 10.1037/h0087468

Slater, A., Tiggemann, M., Firth, B., \& Hawkins, K. (2012). Reality check: An experimental investigation of the addition of warning labels to fashion magazine images on women's mood and body dissatisfaction. Journal of Social and Clinical Psychology, 31, 105-122. doi: $10.1521 /$ jscp.2012.31.2.105

Stice, E. (2001). A prospective test of the dual pathway model of bulimic pathology: Mediating effects of dieting and negative affect. Journal of Abnormal Psychology, 110, 124-135. doi: 10.1037/0021-843X.110.1.124

Stice, E., \& Bearman, S. K. (2001). Body-image and eating disturbances prospectively predict increases in depressive symptoms in adolescent girls: A growth curve analysis. Developmental Psychology, 37, 597-607. doi: 10.1037/0012-1649.37.5.597

Stice, E., Schupak-Neuberg, E., Shaw, H. E., \& Stein, R. I. (1994). Relation of media exposure to eating disorder symptomatology: An examination of mediating mechanisms. Journal of Abnormal Psychology, 103, 836-840. doi: 10.1037/0021-843X.103.4.836

Stice, E., Spangler, D., \& Agras, W. S. (2001). Exposure to Media-Portrayed Thin-Ideal Images Adversely Affects Vulnerable Girls: A Longitudinal Experiment. Journal of Social and Clinical Psychology, 20, 270-288. doi: 10.1521/jscp.20.3.270.22309

Stroop, J. R. (1935). Studies of interference in serial verbal reactions. Journal of Experimental 


\section{EXPOSURE TO BEAUTY STANDARDS AND INHIBITORY CONTROL}

Psychology, 18, 643-662. doi: 10.1037/h0054651

Thomsen, S. R., Weber, M. M., \& Beth Brown, L. (2002). The relationship between reading beauty and fashion magazines and the use of pathogenic dieting methods among adolescent females. Adolescence, 37, 1-18. doi: 10.1190/1.9781560801986

Thornton, B., \& Maurice, J. (1997). Physique contrast effect: Adverse impact of idealized body images for women. Sex Roles, 37, 433-439. doi: 10.1023/A:1025609624848

Tzelgov, J., Henik, A., \& Berger, J. (1992). Controlling Stroop effects by manipulating expectations for color words. Memory \& Cognition, 20(6), 727-735. doi : $10.3758 / \mathrm{BF} 03202722$

Van Dillen, L. F., \& Koole, S. L. (2007). Clearing the mind: a working memory model of distraction from negative mood. Emotion, 7, 715-723. doi : 10.1037/1528-3542.7.4.715 


\section{APPENDIX}

Sample images used for the exposure manipulation

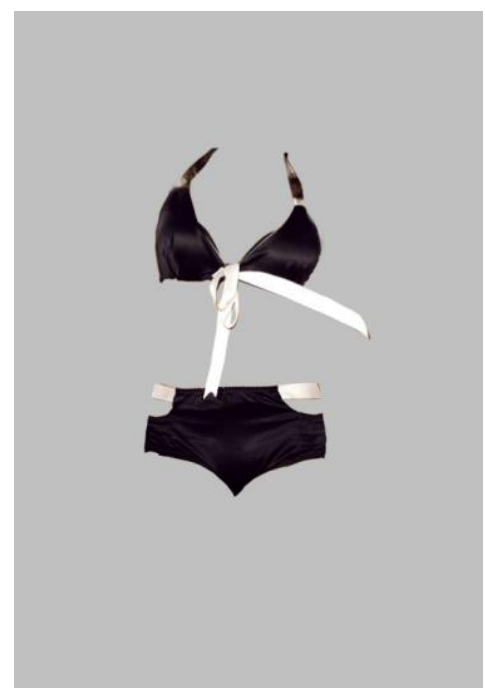

Control condition

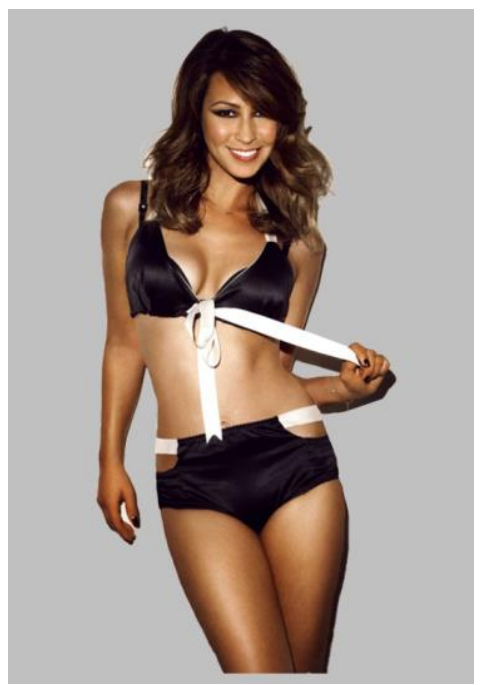

Beauty standard condition 